\title{
An Experimental Study of Conducted EMI Mitigation on the LED Driver using Spread Spectrum Technique
}

\author{
Mohammad Yanuar H, Risanuri Hidayat, and Eka Firmansyah
}

\begin{abstract}
LED driver has the potential to interfere the system of electronic devices if the voltage and current change rapidly. Several previous studies presented various solutions to overcome this problem such as particular converter design, component design, electromagnetic interference (EMI) filters, and spreadspectrum techniques. Compared to other solutions, the spreadspectrum technique is the most potential way to reduce the EMI in LED applications due to its limited cost-size-weight. In this paper, the effectiveness of conducted EMI suppression performance and the evaluation of its effect on LED luminance using spreadspectrum techniques are investigated. Spread-spectrum is applied to the system by modifying the switching frequency by providing disturbances at pin IADJ. The disorder is given in the form of four signals, namely square, filtered-square, triangular, and sine disturbance signals. The highest level of the EMI suppression of about $31.89 \%$ is achieved when the LED driver is given 800 mVpp filtered-square waveform. The highest reduction power level occurs at fundamental frequency reference, when it is given $700 \mathbf{m V p p}$ square disruption signal, is about $81.77 \%$ reduction. The LED luminance level will reduce by $85.2 \%$ when it is given the four waveforms disruption signals. These reductions occur as the switching frequency of the LED driver does not work on a fixed frequency, but it varies in certain bands. LED brightness level has a tendency to generate a constant value of 235 lux when it is given the disruption signals. This disturbance signal causes the dimming function on the system that does not work properly.
\end{abstract}

Keywords-LED driver, conducted, EMI, luminance, spreadspectrum.

\section{INTRODUCTION}

L OW power, high efficiency, and low maintenance contribute to the popularity of LED use in a variety of lighting applications [1]-[4]. Its durability, eco-friendliness, and less composition of poisonous substances compared to other types of lighting make the LEDs become a suitable option [5]-[10]. However, the LED driver also has weaknesses which include fundamental and harmonic frequencies that are emitted through conducted and radiated mechanism [11], [12]; this emission is called electromagnetic interference (EMI). As a result, LED systems do not meet the EMC standards [11], [13]-[15].

The EMI becomes a critical thing because many countries now provide more stringent requirements on all electronic

Mohammad Yanuar H is is a Lecturer at Electrical Department, Politeknik Caltex Riau,Pekanbaru, Indonesia. Currently, $\mathrm{He}$ is a $\mathrm{PhD}$ Student at the Department of Electrical Engineering and Information Technology, Gadjah Mada University, Yogyakarta 55281, Indonesia e-mail: yanuar@pcr.ac.id

Risanuri Hidayat and Eka Firmansyah are with Department of Electrical Engineering and Information Technology, Gadjah Mada University, Yogyakarta 55281, Indonesia. products. Now they have to comply with the EC EMC Directive and the Federal Communications Commission (FCC) in the United States and Europe. However, the EMI in the power supply is hard to remove because of the high power and the broad spectrum (up to $100 \mathrm{MHz}$ ) [16]. Additionally, noise can be even conducted into other parts of the system through the power line. Various ways are used to overcome the EMI generated by the LED systems, including converter designs [12], [17]-[25], components design [26]-[29], the EMI filter [25], [30] and the spread-spectrum techniques [?], [6], [11], [14], [31], [32]. However, the spread-spectrum technique is the most inexpensive and efficient solutions to mitigate the EMI.

All the LED drivers have to comply with the limits specified by CISPR 22 in the USA and the European Norm EN55022. The limits given to the CISPR 22 and the EN55022 standard are intended for devices related to computers and communications. It has been adopted as a common limit for all electronic products, including the lighting. In this paper, conducted EMI mitigation is done by applying the spread-spectrum technique in buck topology LED driver and observing its effect on the LED luminance. The spread-spectrum technique is applied by giving disturbance to the system with four profiles of waveform signals, namely square, filtered-square, triangle, and sine waveform signals. The effectiveness in mitigating the effects of the conducted EMI on LED luminance is considered. This work performs an experiment to investigate the impact of the effectiveness of mitigating conducted EMI using the spread-spectrum technique on the LED luminance.

\section{Conducted EMI Mitigation IN LED DRIVER}

EMI is the energy generated from periodic sources where most of the energy is concentrated at a single fundamental frequency. The influence of the unwanted signal can limit the operation of electronic devices and systems around them. Several government institutions have set the amount of the EMI emitted by an electronic device or system. Their goal is to reduce the power dissipated and eliminate interference with the function of other electronic devices. The LED drivers have to comply with the limits specified by the CISPR 22 as shown in Fig.1.

One of the methods to reduce the EMI amplitude is by using variable switching frequency, which is known as the spreadspectrum techniques [33]. In this case, the switching converter does not work at a fixed frequency. The frequency switching 


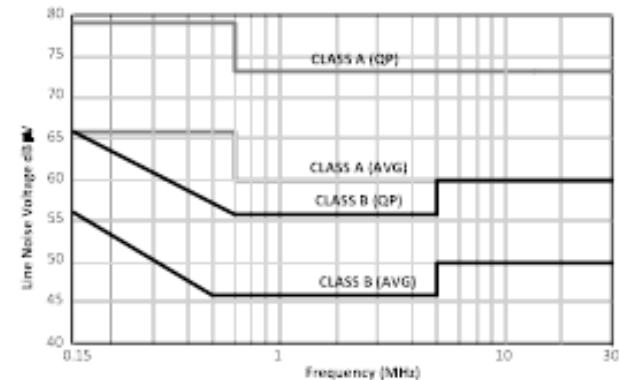

Fig. 1. Conducted Emission CISPR 22 Standard

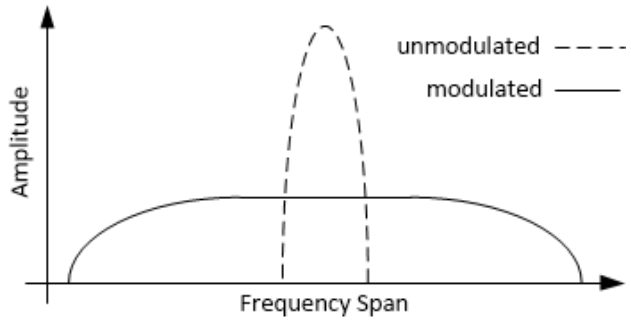

Fig. 2. Representation of Power Level Signal with and without Spreadspectrum

varies within a small range, up and down of the value of the base. It has a wider spectrum with lower amplitude. It is intended to spread a centralized energy into the frequency band, as shown in Fig.2.

The spread-spectrum technique was first used to mitigate the EMI in the LED driver in 2008 [31]. In this research, switched pulses are distributed over a wider band, resulting in the lower EMI compared with linear PWM by using Gated PWM (GPWM) techniques. Spreading the switching frequency by using frequency jittering block is proposed to overcome the problems of the EMI on LED dimming module [6]. PWM dimming circuit is composed of a selector and comparator. Large numbers of a reference voltage are needed to achieve different frequencies. Every frequency will be particular representable value. Different reference voltages are obtained by utilizing a simple resistance divider. The use of Spread-Spectrum Frequency Modulation (SSFM), where the switching frequency will swing at a particular frequency band, up and down of the fundamental frequency, will produce a wider spectrum and lower amplitude [11]. Frequency cannot be varied an extravagant amount, because it will affect the average current through the LED. The mitigation technique uses 10th order linear feedback shift register (LFSR) to generate pseudo-random vectors proposed to control the PWM that shows promising results [14]. The system is designed in TSMC CMOS process to meet the EMI standards for the LED driver without sacrificing stability and efficiency. The measurement results show that the proposed timing can reduce the EMI by $14 \mathrm{~dB}$ while maintaining a constant current of 120 $\mathrm{mA}$. The probabilistic PWM (PPWM) pulse generation using modified Linear Feedback Shift Register (LFSR) is proposed to address the EMI [32]. The emergence frequency, peak value, and variety of incoming currents can be reduced by the PPWM control that can effectively eliminate the problem

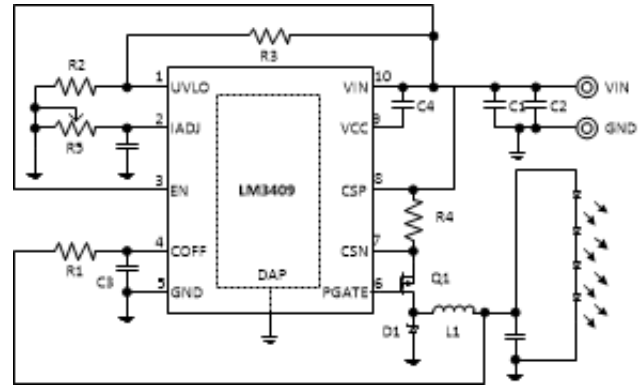

Fig. 3. LM3409 LED Driver Buck Converter Evaluation Board Schematic

of temperature and the EMI. The test results showed that the PPWM dimming could reduce the average value of the peak inflows of up to $5 \%$ and a variation of up to $35 \%$, with the cost of the hardware that is affordable. The Chaos-Based Pulse Width Modulation (CPWM) is used in the Half-Bridge Resonant (HBR) LED driver to suppress the harmonics [?]. The CPWM is proposed to suppress the EMI in high-power LED driver. The CPWM circuit is used to generate chaos analog circuits by adopting Chua oscillator. By using a chaotic external signal to the PWM control circuit in the power supply, the HBR can suppress the EMI. The most substantial reduction of the EMI by $24 \mathrm{~dB}$ is obtained when using a switching frequency of $565.56 \mathrm{kHz}$ at R14 $=100 \mathrm{k} \Omega$.

\section{RESEARCH METHOD}

The core of the experimental setup is the LM3409 LED driver demonstration board buck topology. The evaluation board is designed to drive 4 LEDs $(\mathrm{VO}=15 \mathrm{~V})$ at average maximum current LED (ILED=1A) of the DC input voltage $(\mathrm{VIN}=24 \mathrm{~V})$. Switching frequency $(\mathrm{FSW}=525 \mathrm{kHz})$ is the frequency to be achieved for the nominal point of operation though the FSW that varies throughout the operating range. The LM3409 demonstration board schematic converter as shown in Fig.3 can accept input voltages with the range of $6 \mathrm{~V}$ to $42 \mathrm{~V}$. If the input voltage drops below the LED string voltage, the converter drops out. It is ideally $\mathrm{VO}=\mathrm{VIN}$.

Two types of tests were performed on the LM3409 evaluation board to see the effect of the spread-spectrum technique in mitigating the conducted EMI and its influence on the LED luminance. The LED driver was in normal operation when the spread-spectrum techniques were implemented in the system. The Spread-spectrum techniques were applied to the system by modifying the switching frequency by providing disturbance at IADJ pin with the four types of different signal characteristics as shown in Fig. 4. The fourth signal amplitudes varied from 300 to $1200 \mathrm{mVpp}$ at $525 \mathrm{kHz}$ fixed frequency. Testing the LED driver was done using the standard CISPR 22. Measurements were performed in a frequency range of 150 $\mathrm{kHz}$ to $925 \mathrm{kHz}$. LISN was used in testing to create a uniform test environment to clarify the effect of the method chosen. By using these methods and arrangements, the difference between a constant switching frequency as a reference and spreading switching frequency could be distinguished easily. 


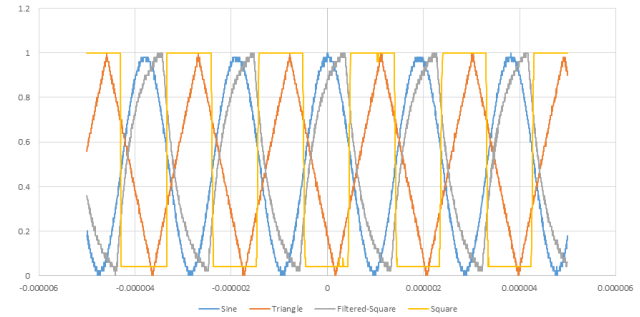

Fig. 4. Disturbance Source Signal

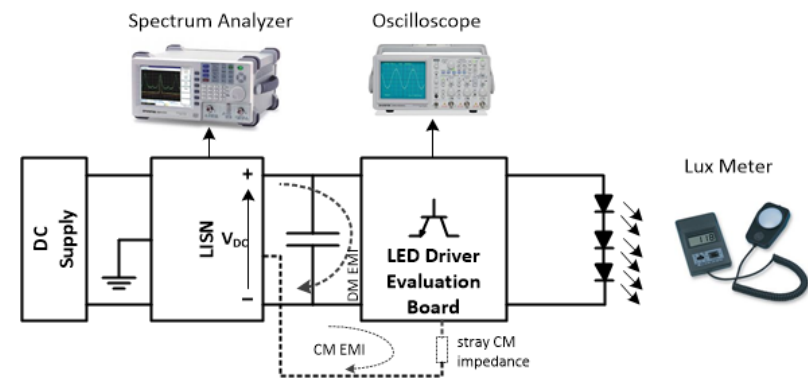

Fig. 5. Block Diagram of Performance Testing Constant-Frequency Reference LED Driver

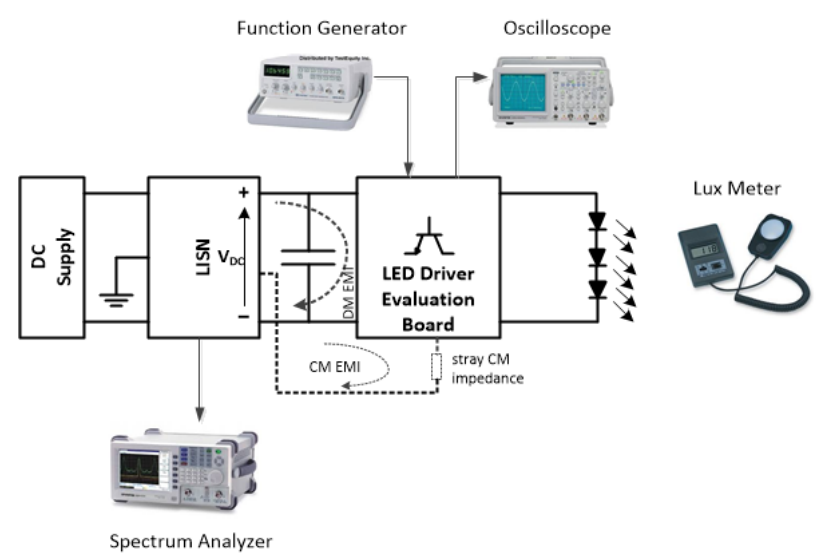

Fig. 6. Block Diagram of Performance Testing LED Driver by Giving Disturbance to IADJ

\section{A. Constant-Frequency Reference Converter}

The experimental setup was carried out under normal conditions without any interference on the IADJ pin with an input voltage 24 volts. In the IC LM3409, there is the IADJ pin connected with R5 variable resistor (250 k) (Fig. 3). The IADJ pin has the function to adjust the LED luminance by providing the output voltage and current variations. The block diagram of the test can be seen in Fig. 5. The parameters measured in this experiment are a spectrum EMI and the changes of the LED luminance when the IADJ changes from $0.01 \mathrm{~V}$ to 1.2 V.

\section{B. LED Driver Performance Test by Feeding Disturbance Signal to IADC Test Point}

This experiment step was done with the conditions of disturbances in the IADJ pin when potentiometer R5 was set at a minimum value. Signal disturbances in the form of the four

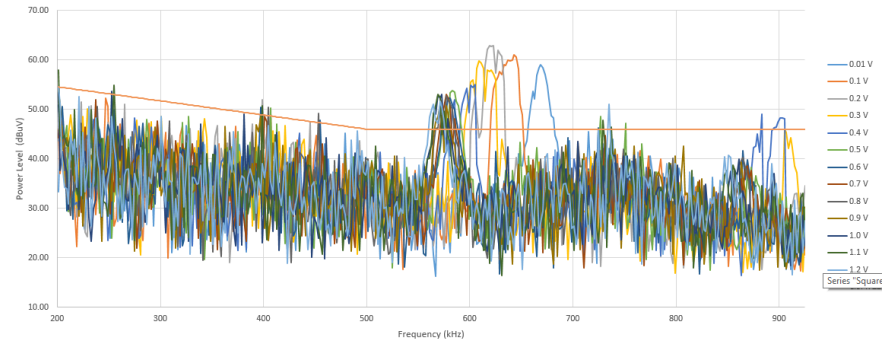

Fig. 7. Interference Power Level when IADJ Voltage Changing from 0.01 Vpp-1.2 Vpp

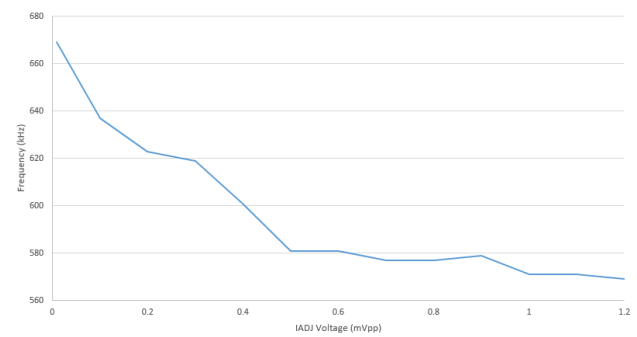

Fig. 8. IADJ Voltage Vs Frequency

different types of the signals namely square, filtered-square, sine, and the triangle were generated by a function generator. The disturbance waveform signal was set at 300 to $1200 \mathrm{mVpp}$ and frequency of $525 \mathrm{kHz}$. The experimental block diagram for this condition is shown in Fig. 6.

\section{Result And Analysis}

\section{A. LED Driver Performance Test in Constant-Frequency Ref- erence}

The EMI is generated when the voltage of the point IADJ varies between 0.01 to $1.2 \mathrm{Vpp}$. It can be seen in Fig. 7 . The LED driver will work on a particular frequency when the voltage at the pin IADJ is set at a specific value. Comparing with the CISPR 22 Class B, the level of power generated at each different voltage exceeding the limit is set by the CISPR 22 Class B. Total power levels generated are almost the same in every voltage with an average value of $33.24 \mathrm{dBV}$. In the $563 \mathrm{kHz}$ to $683 \mathrm{KHz}$ frequency range, generated power levels above the maximum value are set by CISPR. The highest power level exceeding the standard occurs when the IADJ test point is given voltage of $0.2 \mathrm{Vpp}$ at a frequency of $627 \mathrm{KHz}$. When constant-frequency reference compared with standard CISPR, there is reduction about $34.57 \%$.

Voltage changing in the IADJ pin changes the LED driver switching frequency. When the IADJ voltage increases, the switching frequency has a tendency to decrease, as shown in Fig. 9. Besides affecting the switching frequency, the IADJ voltage changes also affect the LED luminance. When the IADJ voltages change, the LED luminance also changes as shown in Fig. 9.

\section{B. LED Driver Performance by Feeding Disturbance on IADJ}

1) Filtered-square Signal: When it is given filtered-square profile signal disturbance on the IADJ pin, the power level is 


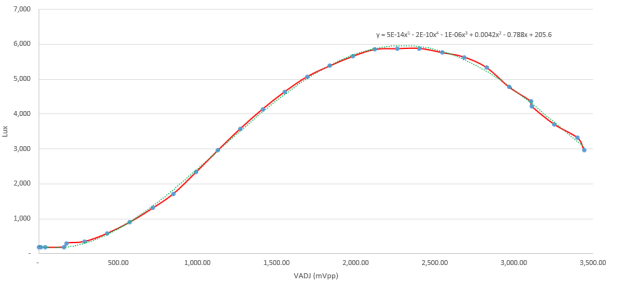

Fig. 9. LED Luminance Vs IADJ Voltage

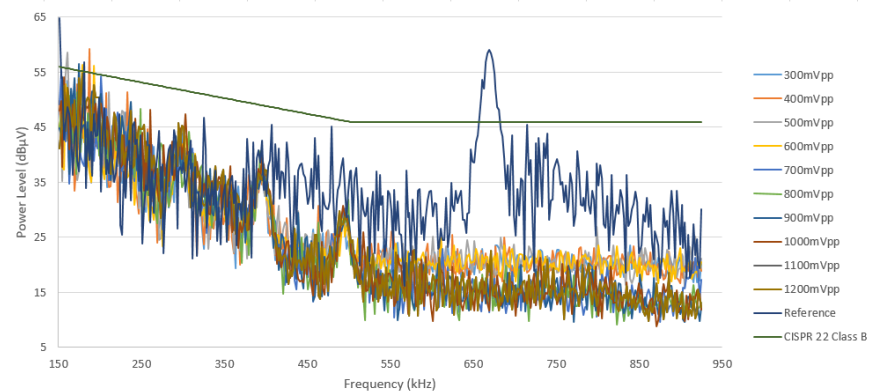

Fig. 10. Interference Power Level when Given Filtered-square Disturbance Signal

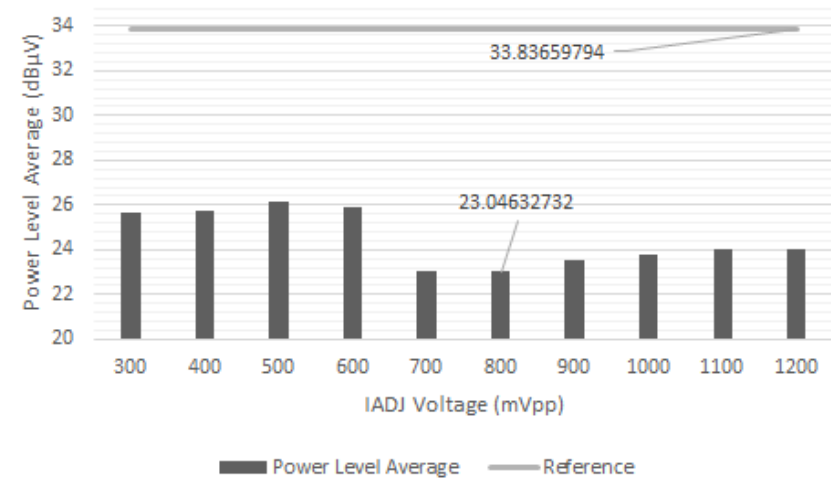

Fig. 11. Power Level Average Vs Voltage of Filtered-Square Disturbance Signal

obtained as shown in Fig. 10. There is a decrease in power level when given filtered-square signal interference on IADJ pin with voltage varies between 300 to $1200 \mathrm{mVpp}$. The power level reduction occurs as the the LED driver is no longer working on a fixed switching frequency, but it works on a certain frequency band. The average power level generated by the different voltage is about $24.49 \mathrm{dBV}$. When compared with reference signal power level, there is a reduction about $9.34 \mathrm{dBV}$. In Fig. 11, the most reduction average power level of $31.89 \%$ occurs when it is given $800 \mathrm{mVpp}$ amplitude disruption signal. The highest reduction power level of $80 \%$ occurs at fundamental frequency reference when it is given 700 $\mathrm{mVpp}$ disruption signal. The overall power level is generated by the filtered-square signal below the established standards CISPR 22 Class B. Meanwhile, the LED luminance when it is given the disruption of the filtered-square waveform varying 300 to $1200 \mathrm{mVpp}$ has a constant value of about 234.8 lux. In Fig. 12, there is $27 \%$ to $93 \%$ reduction of the LED luminance.

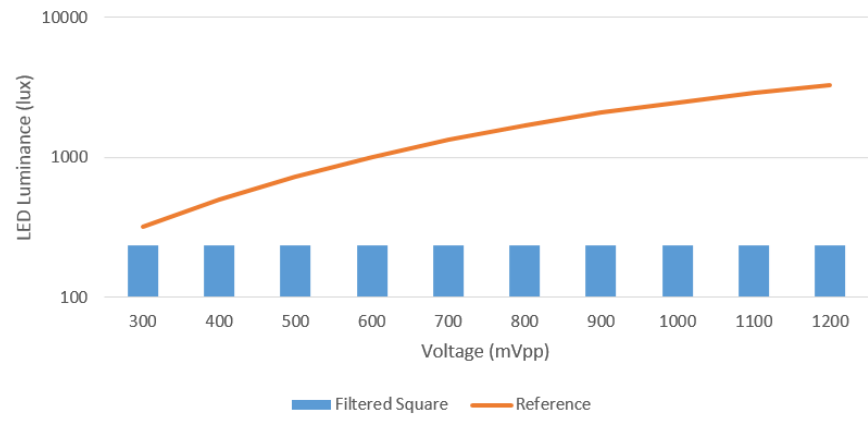

Fig. 12. LED Luminance Vs Voltage of Filtered-Square Disturbance Signal

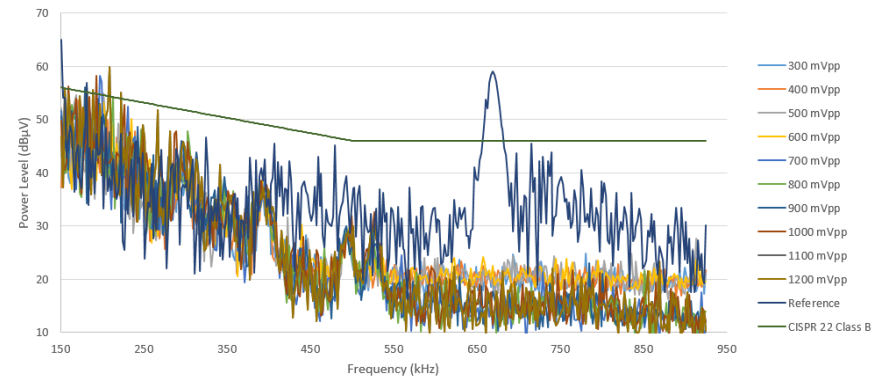

Fig. 13. Interference Power Level when Given Square Disturbance Signal

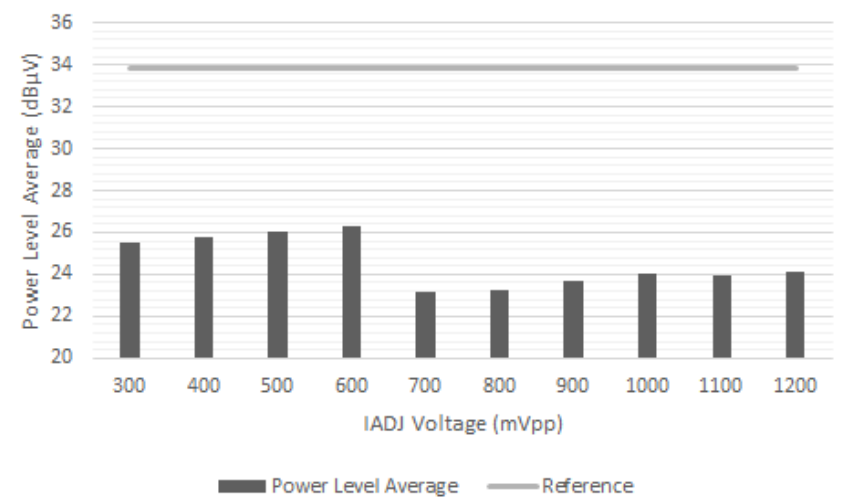

Fig. 14. Power Level Average Vs Voltage of Square Disturbance Signal

The highest reduction of the LED luminance of $93 \%$ occurs at $1200 \mathrm{mVpp}$.

2) Square Signal: When it is given square profile signal disturbance on the IADJ pin, the power level is obtained as shown in Fig. 13. There is a decrease in power level when it is given square signal interference on the IADJ pin with the voltage that varies between 300 to $1200 \mathrm{mVpp}$. In line with the previous treatment, the power level reduction occurs as the LED driver is no longer working on a fixed switching frequency, but it works on a certain frequency band. The average power level generated by the different voltage is around $24.58 \mathrm{dBV}$. When it is compared with reference signal power level, there is a reduction about $27.34 \%$.

In Fig.14, the maximum reduction of average power level occurs when it is given $700 \mathrm{mVpp}$ amplitude disruption signal is about $31.54 \%$. 14. The highest reduction power level occurs at the fundamental frequency reference; when it is given 1000 


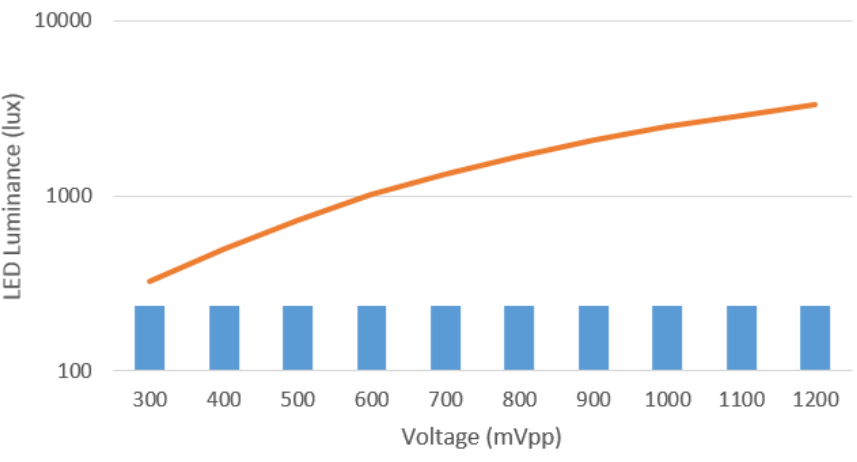

Square $\longrightarrow$ Reference

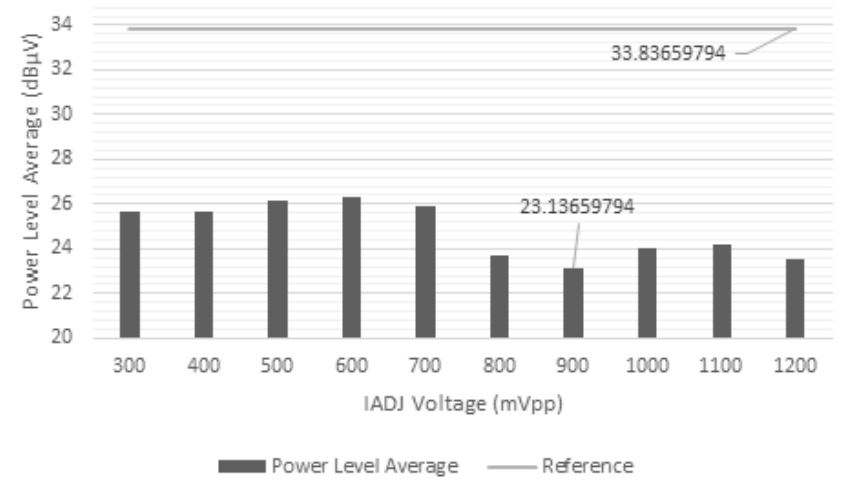

Fig. 17. Power Level Average Vs Voltage of Sine Disturbance Signal

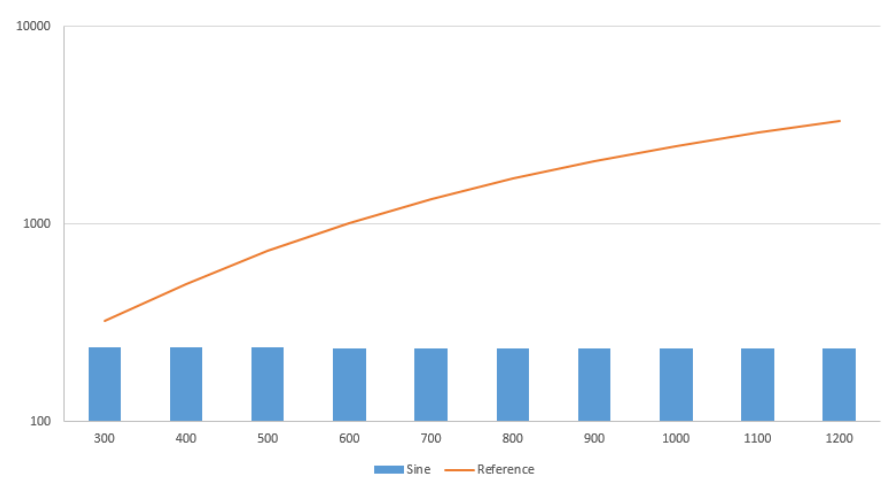

Fig. 18. LED Luminance Vs Voltage of Sine Disturbance Signal

produced by the LED when it is given the disruption of the sine waveform varies from 300 to $1200 \mathrm{mVpp}$ has a relatively constant value of about 235 lux, as seen in Fig. 18. There is also $27 \%$ to $93 \%$ reduction of the LED luminance. The highest reduction LED luminance of $93 \%$ occurs at $1200 \mathrm{mVpp}$.

4) Triangle Signal: The triangle profile signal disturbance on the IADJ pin (obtained power level) is shown in Fig. 19. There is a decrease in power level when it is given sine signal disturbance on the IADJ pin with the voltage that varies from 300 to $1200 \mathrm{mVpp}$. The power level reduction occurs as the LED driver is no longer working on fixed switching frequency, but it works on a certain frequency band. The average power level generated by the different voltage is about $24.965 \mathrm{dBV}$. When compared with the reference signal power level, there is a reduction about $26.22 \%$. The maximum reduction of the average power level occurs when it is given $800 \mathrm{mVpp}$ amplitude disruption signal which is about $30.01 \%$, as seen in Fig. 20.

The highest reduction power level occurs at the fundamental frequency reference. When it is given $900 \mathrm{mVpp}$ disruption signal, there is $73.69 \%$ reduction. The overall level of power generated by the triangle signal is below the established standards CISPR 22 Class B. Meanwhile the luminance produced by the LED when given the disruption of the triangle waveform varies from 300 to $1200 \mathrm{mVpp}$ has a relatively constant value of about 235.1 lux, as seen in Fig. 21. There is also $27 \%$ to $93 \%$ reduction of the LED luminance. The of the power generated by the sine signal is below the established standards CISPR 22 Class B. Meanwhile the luminance
The average power level generated by the different voltage 24.82 dBV. When compared with the power level $26.34 \%$. The maximum reduction of the average power leve occurs when it is given $700 \mathrm{mVpp}$ amplitude disruption signa which is about $31.62 \%$, as seen in Fig. 17. The highest reduction power level occurs at the fundamental frequency reference, when it is given $900 \mathrm{mVpp}$ disruption signal, there is $76.9 \%$ reduction, it is quite significant. The overall level 


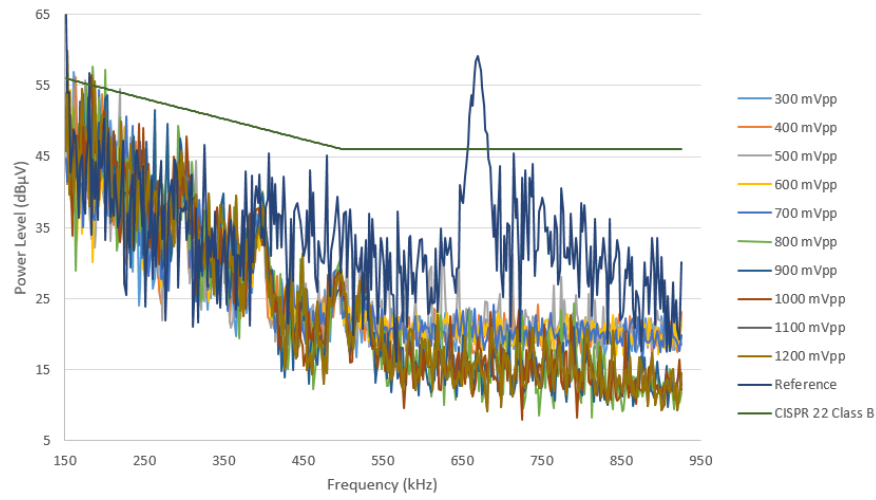

Fig. 19. Interference Power Level when Given Triangle Disturbance Signal

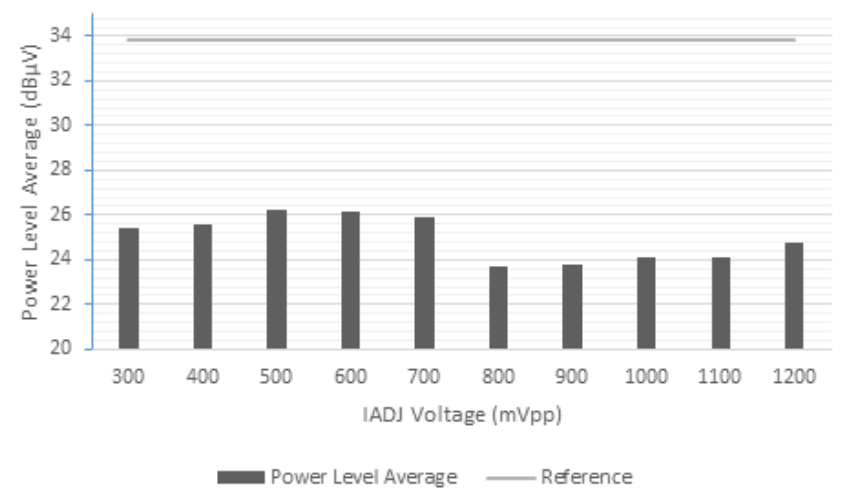

Fig. 20. Power Level Average Vs Voltage of Triangle Disturbance Signal

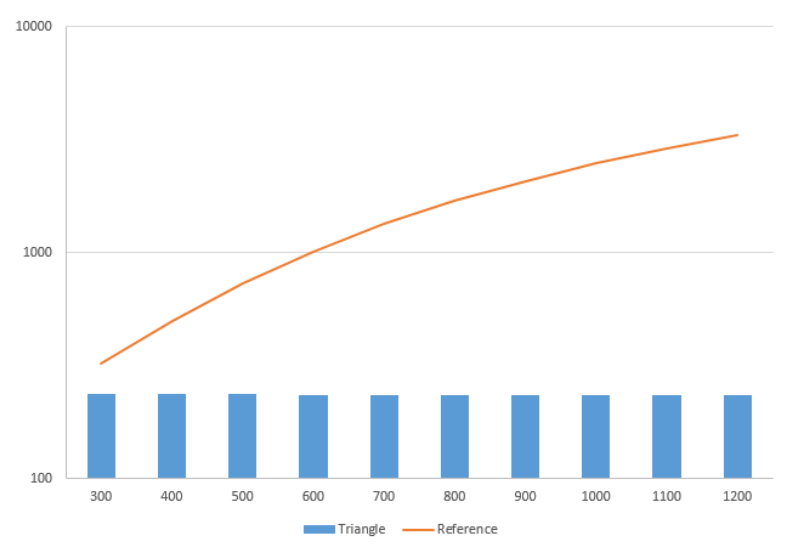

Fig. 21. LED Luminance Vs Voltage of Triangle Disturbance Signal

highest reduction the LED luminance of $93 \%$ occurs at 1200 $\mathrm{mVpp}$.

From the test results, the EMI generated by the LED driver when the pin IADJ is given is the disruption of the four different characteristic waveforms showing that the filteredsquare signal with an amplitude of $800 \mathrm{mVpp}$ has the greatest ability to suppress the EMI compared to three other signals. The filtered-square signal has an average power level of $24.493 \mathrm{dBV}$. The EMI reduction is produced around $31.82 \%$ to reference, as shown in Fig. 22. The LED luminance values decrease significantly and have a tendency to have a fixed

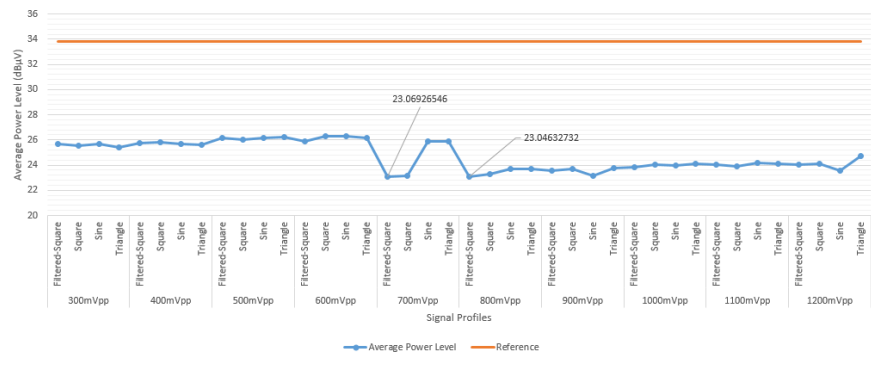

Fig. 22. Four Signal Disturbance Vs Reference Average Power Level

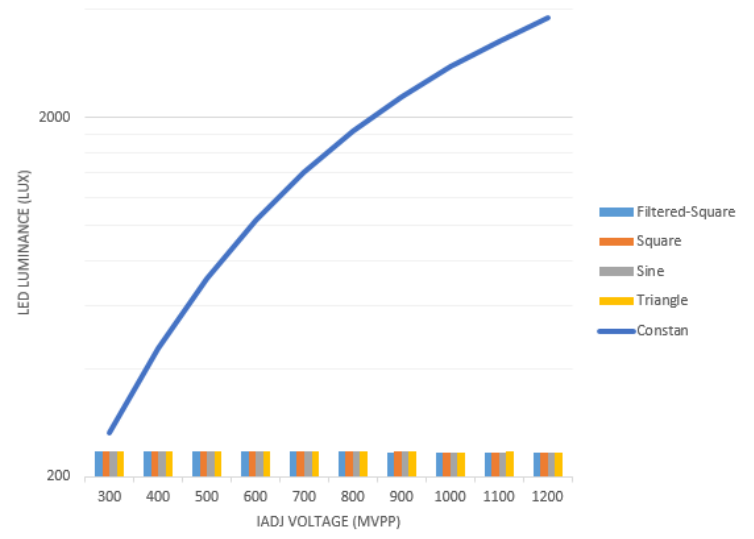

Fig. 23. Four Signal Disturbance Vs Reference LED Luminance

value when the system is given in the form of the four types of the signal interference, as shown in Fig. 23. The highest reduction of the LED luminance of $93 \%$ occurs at $1200 \mathrm{mVpp}$. It means that the dimming function provided by the system does not work.

\section{CONCLUSION}

The spread-spectrum technique can be implemented by giving the IADJ pin of the four types of the waveform signals with varying amplitude. The LED driver is no longer working on a fixed frequency, but it works on some frequency switching. This technique can reduce the EMI that is generated by the power converter, but it will cause a dimming function that can not work according to its function. The LED brightness level has a tendency to produce a constant value of 235 lux when it is given the four waveforms disruption signal, its $27 \%$ to 93\% LED luminance reduction towards reference. The most powerful level average reduction of around $31.89 \%$ is obtained when the LED driver is given $800 \mathrm{mVpp}$ filtered-square waveform disturbance on the IADJ pin. The most efficient reduction power level occurs at the fundamental frequency reference, when it is given $700 \mathrm{mVpp}$ square disruption signal of about $81.77 \%$ reduction.

\section{REFERENCES}

[1] M. S. Shur and A. Zukauskas, Solid-State Lighting: Toward Superior Illumination, Proceedings of the IEEE, vol. 93, pp. 1691-1703, 2005

[2] I. L. Azevedo,M. G. Morgan, and F. Morgan,The Transition to SolidState Lighting, Proceedings of the IEEE, vol. 97, pp. 481-510, 2009.

[3] W. R. Ryckaert, K. A. G. Smet, I. A. A. Roelandts, M. Van Gils, and P. Hanselaer,Linear LED Tubes Versus Fluorescent Lamps: An Evaluation,Energy and Buildings, vol. 49, pp. 429-436, 2012. 
[4] A. D. N. Ndokaj, A.,LED Power Supply and EMC Compliance, Energy Conference and Exhibition (ENERGYCON) IEEE International, pp. 254 - 258, 2012.

[5] C. Qi, C. Quan, and L. Xiaobing,Fast Estimation of LED's Accelerated Lifetime by Online Test Method, Electronic Components and Technology Conference (ECTC), pp. 1992-1995,2014.

[6] Zheng, J., Han, Z., and Luo, S. System level design of a LED lighting driver based on switching power supply, Asia Pacific Conference on Postgraduate Research in Microelectronics \& Electronics (PrimeAsia), 309312, 2009

[7] S. P. Y. C. W. T. B. J. Huang,Characterizing LEDs for Mixture of Colored LED Light Sources, Electronic Materials and Packaging, 2006. EMAP 2006. International Conference on, Kowloon, pp. 1-5, 2006.

[8] S. C. H. L. L. L. M. S. J. Y. C. Hsieh,Assessment of Energy-Efficient LED Street Lighting Through Large-Scale Demonstration, Renewable Energy Research and Applications (ICRERA), pp. 1 - 5, 2012.

[9] C. P. X. L. P. Z. L. X. X. Liu,RGB High Brightness LED Modules for Projection Display Application, Display Technology, vol. 7, pp. 448 453,2011

[10] T. F. C. Wu, C. C. Wu, C. Y.Lu, P. C., Chen, Y. R., Sequential Color LED Backlight Driving System for LCD Panels with Area Control,Power Electronics Specialists Conference, 2007. PESC 2007, Orlando, FL pp. 2947 - 2952, 2007.

[11] L. Dong, Y. Ye, and L. He,A Novel PWM Controller IC for LED Driver with Frequency Spread, Power and Energy Engineering Conference (APPEEC), Asia-Pacific, pp. 1-4, 2010.

[12] D. G. Lamar, J. Sebastian, M. Arias, and M. M. Hernando,A LowCost AC-DC High-Brightness LED Driver with Power Factor Correction Based on Standard Peak-Current-Mode Integrated Controllers,Energy Conversion Congress and Exposition (ECCE), 2010 IEEE, pp. 463-470, 2010.

[13] K. O. Mainali, R. ,Conducted EMI Mitigation Techniques for Switch Mode Power Converters A Survey, Power Electronics, IEEE Transactions vol. 25, pp. 2344 - 2356, 2010.

[14] S. M. W. K. H. Chang,An LED Driver with Active EMI Mitigation Scheme, Electron Devices and Solid-State Circuit (EDSSC), pp. 14,2012 .

[15] W. A. Junying Niu,Yuhong Song, Zhong Li; Halang,Reducing EMI in Half-Bridge Resonant LED Drivers with Chaos-based PWM, Electromagnetic Compatibility (EMC EUROPE), 2013 International Symposium, pp.637-640, 2013

[16] H. Wong, Y. Chan, and S. W. Ma,Electromagnetic Interference of Switching Mode Power Regulator with Chaotic Frequency Modulation, Microelectronics, 2002. MIEL 2002. 23rd International Conference, pp. 577-580, 2002

[17] Y. Liu and Y. Jinming,The Topologies of White LED Lamps' Power Drivers," Power Electronics Systems and Applications,PESA 2009. 3rd International Conference, pp. 1-6, 2009.

[18] G. C. Pasetti, N.,Tinfena F.,Serventi, R.,D’Abramo. P., Saponara. S., Fanucci. L.,Characterization of An Intelligent Power Switch for LED Driving with Control of Wiring Parasitics Effects,Design, Automation \& Test in Europe Conference \& Exhibition (DATE), pp.1-2, 2011.

[19] M. R. Cosetin, P. C. V. Luz, M. F. da Silva, F. Bisogno, J. M. Alonso, and R. N. do Prado,Single-Stage Sepic-Buck Converter for LED Lighting wth Reduced Storage Capacitor,IECON 2012 - 38th Annual Conference on IEEE Industrial Electronics Society pp. 4597-4603, 2012.

[20] M. R. Cosetin, P. C. V. Luz, M. F. da Silva, F. Bisogno, J. M. Alonso, and R. N. do Prado,LongLifetime SEPIC-Buck Integrated Converter for LED Lighting Application,Industry Applications (INDUSCON), 2012 10th IEEE/IAS International Conference, pp. 1-7,2012.

[21] M. R. Cosetin, P. C. V. Luz, E. A. Bitencourt, M. F. da Silva, F. Bisogno, J. M. Alonso, et al.,O-Line Single-Stage SEPIC-Buck Converter for Dimmable LED Lighting with Reduced Storage Capacitor, Power Electronics and Applications (EPE), 2013 15th European Conference,pp. 110,2013 .

[22] K. Junsik, L. Jiyong, and P. Shihong,A Soft Self-Commutating Method using Minimum Control Circuitry for Multiple-String LED Drivers,Solid-State Circuits Conference Digest of Technical Papers (ISSCC), 2013 IEEE International, pp. 376-377, 2013.

[23] W. A. Venturini, E. A. Bitencourt, M. E. Schlittler, M. F. da Silva, R. N. do Prado, and F. E. Bisogno,Analysis and Design Methodology of A Self-Oscillating System Based on Integrated Sepic Half-Bridge for LED Lightning Applications,Power Electronics Conference (COBEP), 2013 Brazilian, pp. 1120-1127,2013

[24] Y. Yang, R. Xinbo, Z. Li, H. Jiexiu, and Y. Zhihong,A Feed-Forward Scheme for an Electrolytic Capacitor-Less AC/DC LED Driver to Reduce Output Current Ripple, Power Electronics, IEEE Transactions, vol. 29, pp. 5508-5517, 2014.

[25] A. K. R. Rasheed,Double Stage Buck Boost Converter For LED Lighting Application, International Conf. on Electrical, Electronics, Mechanical \& Computer Engineering, Cochin, India, pp. 22-29,2014.

[26] Y. z. Xu, W. m. Lin, Y. c. Xu, and Y. j. hao,Inductor Optimize Design for BCM BUCK-PFC in LED Driver,Electric Information and Control Engineering (ICEICE), pp. 2264-2267, 2011

[27] Nielsen, M. A. E. Andersen, and K. S. Meyer,Preliminary Investigations of Piezoelectric Based LED Luminary, Power Electronics and Applications (EPE 2011), Proceedings of the 2011-14th European Conference, pp. 1-9, 2011

[28] L. Keon, L. Dong-Hun, Y. Su-hun, P. Ji-Hyun, and Y. KwangSub,Design of High Dimming Ratio Power-LED Driver with Preloading Inductor Current Methodology,SoC Design Conference (ISOCC), pp. 9$12,2012$.

[29] G. M. Soares, P. S. Almeida, D. P. Pinto, and H. A. C. Braga,A SingleStage High-Efficiency Long-Life Off-Line LED Driver Based on The DCM Cuk Converter, IECON 2012 - 38th Annual Conference on IEEE Industrial Electronics Society, pp. 4509-4514, 2012.

[30] C. Jettanasen and C. Pothisarn,Analytical Study of Harmonics Issued from LED Lamp Driver,Proceedings of the International MultiConference of Engineers and Computer Scientists, Hong Kong, 2014.

[31] L. Svilainis,LED Brightness Control for Video Display Application, Displays, vol. 29, pp. 506-511, 2008.

[32] J. H. Ahn,Implementation Of An Led Tile Controller for High-Quality Image Display, Displays, vol 34, pp. 17-26, 2013.

[33] D. Gonzalez, J. Balcells, A. Santolaria, J. C. Le Bunetel, J. Gago, D. Magnon, et al.,Conducted EMI Reduction in Power Converters by Means of Periodic Switching Frequency Modulation, Power Electronics, IEEE Transactions, vol. 22, pp. 2271-2281, 2007. 